\title{
Developing and Maintaining Interest in School Algebra
}

\author{
Mark Prendergast, John O’Donoghue \\ NCE - MSTL, University of Limerick, Ireland
}

\begin{abstract}
In Ireland, concern is widespread regarding the poor take-up of Higher Level ${ }^{1}$ mathematics in secondary education. This has serious implications for the follow-on study of mathematics at degree level. The solution for such a complex problem is in no way straight forward. Undoubtedly, an important step is to improve the quality of mathematics teaching at second level. A variety of teaching methods must be used to ensure more appealing lessons that engage the learning styles of students. Past styles relied too much on 'talk and chalk', followed by the repetitive practice of skills and algorithms. Although such a style of teaching is undoubtedly needed to some extent in mathematics, this must be combined with alternative approaches which include group work, discovery learning and problem solving. The challenge for the authors is to design a framework for the development of a teaching intervention that will strike the right balance between approaches, while promoting student achievement and maintaining student interest in the topic.
\end{abstract}

\section{Introduction}

The poor uptake of Higher Level Junior and Senior Cycle (lower and upper secondary education) mathematics is one of the main concerns regarding mathematics education in Ireland at present. In 2010, figures show that only 45 per cent of the Junior Cycle cohort took the Junior Certificate Higher Level mathematics' examination [20]. More worryingly only 16 per cent opted for the Higher Level Leaving Certificate examination [20]. Consequently, concern is widespread in many third level institutions regarding the mathematical ability of their entrants. Countless professions particularly those in science, engineering and technology are in danger of lower standards as a result of graduate

\footnotetext{
1 There are three levels of mathematics in the Irish school examination system with the highest referred to as Higher, a lower level referred to as Ordinary and the lowest level that can be taken is called Foundation.
}

deficiencies in mathematics. This has serious repercussions for the Irish economy, particularly in relation to the technology and industrial sectors. In order to meet the future needs of the economy, the authors submit that a figure in the region of at least 60 - 70 per cent of students must sit Higher Level Junior Certificate mathematics. This figure is in line with other subjects at this level and with government targets. Hence, the main aim of this research paper is to design a framework which will be used to develop an intervention program comprised of effective teaching materials for Junior Cycle level. These materials will be designed to promote and maintain student interest in mathematics, specifically focused on the topic of algebra. The long term aspiration is to increase the numbers taking Higher Level mathematics at Junior Cycle Level.

\section{Research Background}

\subsection{Importance of Student Interest}

Many believe that the key to boosting the numbers taking Higher Level mathematics in Ireland is to increase students' interest in the subject. While effective teaching methodologies and resources are of paramount importance, such efforts are futile unless students have a desire and motivation to learn. This is backed up by Hidi and Harackiewicz [8] who established that the key to impacting an individual's academic performance lies in increasing the individual's interest in the particular domain. Current research figures in Ireland show that there is much work to do in this respect. Statistics released by PISA [16] show that less than half (48 per cent) of Irish students agree that they are interested in the things they learn in mathematics. This figure was slightly down on the OECD average of 53 per cent. In addition only 32 per cent of Irish students declare that they look forward to their mathematics lessons, while only 33 per cent concur that they do mathematics for the enjoyment. The same study disclosed that over two-thirds of Irish 15 year olds 'often feel bored' at school, while the OECD average for this was under 50 per cent [16]. Such figures provide evidence that students are reluctant and unwilling to engage in domains which have little use 
or relevance to their own lives, for example the topic of algebra.

\subsection{Rationale for choosing Algebra}

Throughout the literature algebra is highlighted as an important domain within mathematics and indeed everyday life [4: 8]. However students are unable to see the everyday use of algebra in their own lives. Hence, despite the topic's obvious importance, Artique and Assude [1] ascertain that many students see algebra as the area where mathematics abruptly becomes a non understandable, confusing world. Evidence of this confusion can be found in Irish classrooms. Chief Examiners' reports have identified algebra as an area of weakness over the past number of years [3]. Questions related to algebra are often the lowest scoring questions on the paper or are continually avoided [3]. The current school approach to the domain is totally inadequate. What students learn is a collection of rules to be memorised and steps to be followed having no logical coherence, very little connection with previously learned arithmetic, and no applications in other school subjects or in the outside world [12].

With this in mind, the challenge is to find ways to make the power of algebra available to all students and to find ways of teaching that allow students to learn with understanding and generate a genuine interest in the topic. Different methods aimed at making learning more meaningful and interesting for these students have been proposed. This research intends to examine such methods and develop an intervention program comprised of materials for effective teaching of algebra.

\section{Intervention}

\subsection{What is an Intervention?}

Intervention literature proposes that an intervention is a new idea or conceptualisation that is intended to result in a positive outcome rather than the negative one that would ordinarily occur [17]. It means imposing a change or something new (an activity strategy or approach) in an already ongoing relationship with the goal of improving it [17]. The situation outlined in the Introduction warrants an intervention action to arrest the decline of fallings numbers sitting Higher Level Junior Certificate mathematics. This action is necessary to reinforce the flow of adequately prepared mathematical candidates in sciences, engineering and technology courses at third level. It is hoped that boosting the numbers sitting Higher Level for the Junior Certificate will strengthen the numbers who proceed to take Higher Level mathematics for the Leaving Certificate and ultimately advance to study mathematics at third level. From the perspective of this paper, the authors define the term intervention for use in this study as:

'A course of action to address a problematic situation (numbers sitting Higher Level Junior Certificate mathematics) designed to change beliefs, attitudes and behaviour relating to mathematics'.

\subsection{Aim of the Intervention}

As previously outlined in the Introduction, the main aim of the intervention is to promote and maintain student interest in mathematics, specifically focused on the topic of algebra. The intervention plans to increase students' interest by;

o Showing that mathematics can be fun.

0 Engendering a positive attitude to algebra and an appreciation and enjoyment of mathematics

o Establishing personally relevant links between students and algebra.

o Promoting a better student understanding of the relevance of mathematics.

It is hoped that such interest will evolve into a cycle leading to further value, enjoyment and success in the subject, thus increasing the numbers taking Higher Level.

\section{Design of the Intervention}

The design of the intervention program is influenced by a framework which integrates three theoretical perspectives. These perspectives will be discussed individually and will be utilised for developing the intervention program specific to Algebra and improving student interest in mathematics at Junior Cycle education

\subsection{Theoretical Perspectives}

The theoretical perspectives include pedagogical principles and two models which provide the foundations for a viable framework. The pedagogical principles incorporate three different learning theories, while the models include a model for conceptualising algebraic activity and a model of interest development. Each of these will be discussed individually and will have influential roles in the design and development of the teaching materials.

\subsubsection{A Model for Conceptualising Algebraic Activity}

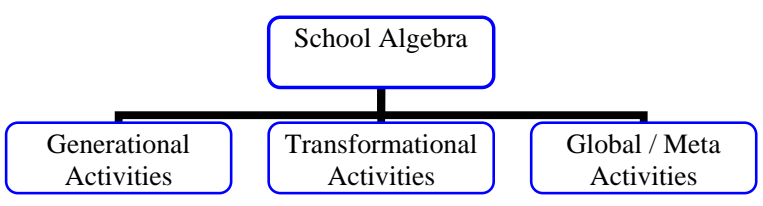

Figure 1. Kieran's Model of Algebraic Activity 
As can be evidenced for the above figure, Kieran's [10] model identifies three important components of school algebra namely;

o Generational activities - promote understanding.

o Transformational activities - rule based manual symbol manipulation.

o Global, meta-level activities - give purpose to the activities.

The objective for the framework based on Kieran's model is to find a balance between algebraic activities. In Ireland current research claims that transformational activities in school algebra are prioritised to the detriment of generational and global meta-level activities [3]. As a result of an over reliance on the text book, teachers are emphasising the technical work while neglecting the conceptual aspects in algebra learning. Kieran's framework acknowledges that teachers must place emphasis on each particular type of algebraic activity. Each activity is important. Techniques and conceptual understanding must be taught together rather than in opposition to each other. Algebraic thinking and manipulation provide the tool for explaining and justifying [11]. The global/ meta level is also important because it gives purpose to the activities. Students are provided with contexts which encourage them to seek reasons for why something works.

Kieran's model for algebraic activity will influence the design of the framework in relation to algebra. However, another model is needed to influence the design in relation to interest development.

\subsubsection{The Four Phase Model of Interest Development}

A review of interest in the literature identifies two main types of interest, namely;

- Situational Interest - certain conditions and/ or stimuli in the environment focus attention, and generate an immediate affective reaction that may or may not last [8:152].

- Individual interest - this is a relatively stable personal disposition that develops over time in relation to a particular topic or domain and is associated with increased knowledge, value and positive feelings [8:152].

Building on this Hidi and Renninger [9] have created a model for developing interest and suggest its potential for supporting an education intervention. The model proposes a four phase model of interest development and identifies situational interest as providing a basis for an emerging individual interest. Both situational and individual interests have been described as consisting of two stages. Situational interest involves a stage in which interest is triggered and a subsequent stage in which interest is maintained. In individual interest, the two stages include an emerging individual interest and a welldeveloped individual interest. The proposed fourphase model as denoted by Figure 2, integrates these conceptualisations. The first phase of interest development is a triggered situational interest. If sustained, this first phase evolves into the second phase, a maintained situational interest. The third phase, which is characterised by an emerging individual interest, may develop out of the second phase. The third phase of interest development can then lead to the fourth phase, a well-developed individual interest.

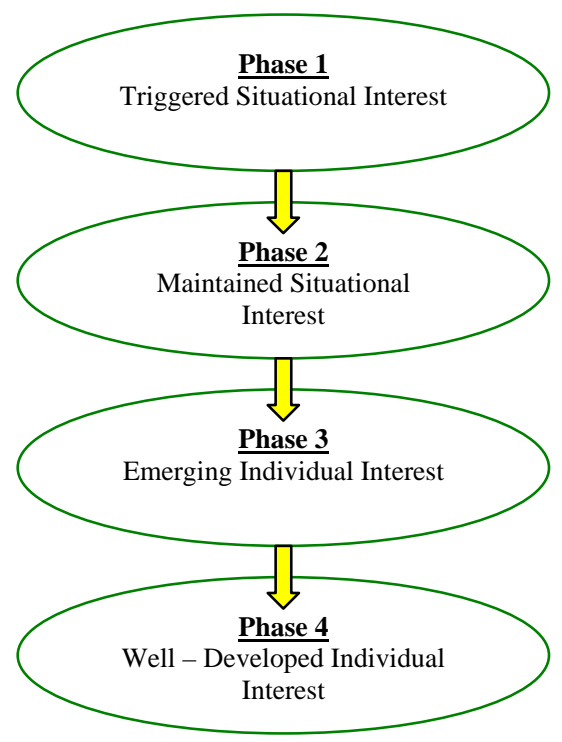

Figure 2. Interest Development: A Four Phase Model

The length and character of a given phase is likely to be influenced by individual experience and temperament [9]. The phases are considered to be sequential and separate, and represent a form of progressive development in cases where interest is supported and sustained [9]. However, if not supported and sustained any phase of interest development can become inactive, retreat to a previous phase, or disappear altogether.

Hidi and Renninger's model provide a structure for the framework in which each student's interest can be stimulated, nurtured and maintained throughout the intervention. In a class of thirty students, there will be many differing levels of interest amongst students. Teachers must be aware that in one particular lesson, they may encounter students who have no personal interest in the topic and also students who are very passionate about the topic. The four stages proposed by Hidi and Renninger acknowledge this and suggest teaching strategies and tasks which can support students' interest whether they are in the first stage or the last stage. However, 
pedagogical principles also need to be integrated into the framework.

\subsubsection{Pedagogical Principles}

These principles were decided upon through an examination of three well known and individually contrasting learning theories namely behaviourism, social learning theory and constructivism.

\section{A. Behaviourism Learning Theory}

The behaviourism learning theory focuses on modifying behaviours that will eventually lead to learning [19]. In essence education is an observable change in behaviour, which is measurable and enduring. This is the learning approach used in many traditionally taught classrooms. Accordingly, the approach stresses practices that emphasise rote learning and the memorisation of formulas, single solutions, and adherence to procedures and drills. Learning is considered to have occurred when the correct solution is reached consistently. This stresses the value of the end product rather than the processes involved in getting there. Dean [5] ascertains these methods imply the learning of skills which are not fully understood. Hence, developing curricula solely within a behaviourist framework misses much of the essence of education such as understanding material and developing socially. The approach is often seen as 'anti - mathematical'. Its focus tends to be on the amount taught, rather than on what understandings and meanings have been achieved.

\section{B. Social Learning Theory}

Snowman and Biehler [19] suggest that this learning theory was "based on the premise that neither spontaneous behaviour nor reinforcement was necessary for learning to occur". Hence, it is in somewhat of a contrast to the theory set out by behaviourism. Learning can occur without a change in behaviour. The theory focuses on learning that occurs within a social context. It considers that people learn from observing, imitating and modelling the behaviours, attitudes and emotional reactions of others [15]. Such a process of learning from observation is linked to the work of Vygotsky on social constructivism and the practice of 'scaffolding'. Scaffolding posits that there are four stages of learning, namely;

1. The student observes the teacher,

2. The student performs the task step by step with the teacher,

3. The student performs the skill while being observed by the teacher,

4. The student performs the task unaided.

The social learning theory, using the work of activists such as Bandura, Schunk and Zimmerman, is also used to describe how people become self- controlled and self-regulated learners. "Self-control is the ability to control one's actions in the absence of external reinforcement or punishment" [19: 278]. An example of this would be a student revising notes after each class, even though the teacher does not examine them each day. This takes immense selfcontrol as they receive no praise from the teacher or no immediate high grades. "Self - regulation is when the individual has his own ideas about what is appropriate or inappropriate behaviour and chooses actions accordingly" [17: 4]. Self-regulation is important because students are expected to become increasingly independent learners as they progress through school [19]. They must assume greater responsibility for their own learning and become more self-directed and autonomous learners. Undoubtedly self-control and self-regulation are important traits for educational success. However, many students have difficulty in acquiring and putting to use such skills.

\subsubsection{Constructivism Learning Theory}

Constructivists believe that "learners actively construct their own understandings rather than passively absorb or copy the understandings of others" [14: 60]. Hence, constructivism is in sharp contrast to the social learning theory in which observation, imitation and modelling of others shapes an individual's behaviour.

A constructivist approach to mathematics learning sees the student playing a central role. He / she are active participants in the learning process. Learning depends on the way the learner looks at the situation as people determine their own knowledge. This knowledge evolves from the learners' previous experiences combined with active engagement in new activities.

This constructivist approach to learning is not a new idea. Scholars such as Dewey, Piaget and Vygotsky have contributed much to its explanations. Another such contributor was Jerome Bruner who theorised an early constructivist perspective from which he introduced the concept of discovery learning. Bruner argues that in school, learners become too dependent on other people [19]. They are 'spoon fed' information. Hence, discovery learning takes a different approach. It sees the student doing the majority of the work. The teacher acts as a facilitator in the classroom. The teacher's concepts and knowledge are not transferred directly to the learner. Instead, according to Simon and Shifter (1991) the teacher attempts "to maximise opportunities for students to construct concepts, give fewer explanations and expect less memorisation and imitation" [14: 60].

Collaborative learning is another major vehicle of constructivism and is one of the main ways in which knowledge can be constructed. It provides a social 
setting in which students can interact with each other. Such interactions lead the students to view ideas and problems from multiple perspectives.

The importance of providing the student with these structured opportunities to engage in exploratory activities in the context of mathematics cannot be overemphasized. The teacher has a crucial role to play in transforming from the 'sage on the stage' to the 'guide on the side'. This is often difficult and disempowering for the teacher. Other disadvantages include the theory's time consuming nature and the high demand placed on the learner. However, the advantages certainly outweigh the disadvantages. Although learning mathematics remains the ultimate objective, learning how to learn mathematics with self-instruction and selfencouragement, is the immediate goal. Thus, each learning theory has different practices and principles. Behaviourism focuses on modifying behaviours that will lead to learning and is the approach used in many traditional classrooms. It stresses practices that emphasis rote learning and the memorisation of formulas, single solutions, and adherence to procedures and drills. However, social learning theory determines that learning can occur without a change in behaviour. The theory considers that people learn from observing and imitating the actions of others. Constructivism on the other hand contrasts with this. It posits that learners actively construct their own knowledge and the teacher merely acts as a facilitator in the classroom.

Each of these theories foreshadow approaches that are important to develop in order for learning to occur. Indeed aspects of each are needed in every learning experience as no one method serves all of the students in a class successfully. However, the authors feel that the learning theory which best serves the needs of this intervention is constructivism. Current styles in Ireland rely too much on rote learning, followed by the repetitive practice of skills and procedures. This behaviourist style of learning is undoubtedly needed to some extent in mathematics, along with elements of the social learning theory such as self-control and selfregulation. However the constructivist learning approach provides an opportunity for students to understand and develop an interest in the material as opposed to memorising for the purpose of attaining good grades. Thus the pedagogical principles will be based principally on this theory.

\section{Implications of Learning Theories for Framework}

In the last section, three of the main learning theories which have developed and been in use in classrooms over the past century were considered. Based on such consideration, it was agreed that constructivism best addressed the issues which contributed to effective teaching for student interest. Constructivism gives recognition and value to new instructional strategies in which students construct their own knowledge. In other words all knowledge is internal to the learner and can only be constructed, not instructed. Essentially, students are encouraged to form new understandings of mathematics using their analysis of the existing ones. Learners using this approach tend to look for similarities and differences within their own experiences as they encounter new situations. Hence, constructivist teaching strategies include more adaptive, experiential and reflective learning activities, some of which will now be reviewed in more detail.

\subsection{Problem Solving}

Problem solving has always been an important mathematical activity but has been given special emphasis in some national curricula in the last twenty years. Teachers present mathematics in context and underline that the main reason for doing mathematics is to solve problems. They emphasise problems rather than rules, and allow a variety of solutions to any one problem. Hence, this shows students that in mathematics, similar to real life, there is also more than one way to solve a problem. Consequently the skills learned through problem solving, such as curiosity and perseverance and higher order thinking, can have application in other, possibly non-mathematical, aspects of a student's life. Students are encouraged to be inventive of their own ways of solving problems and to investigate new ideas. Many believe that the mathematics curriculum should be organised around problem solving. This is as a result of the changing demands of society which require students to apply mathematics to everyday situations.

\subsection{Discovery Methods of Teaching}

Dean [5:71] proposes that discovery in learning is often associated with "rediscovery of knowledge". The material is known by the teachers but their knowledge of it does not prevent the students from constructing their own understanding and discovering it for themselves. Discovery methods of teaching typically take the form of directed discovery, guided discovery or free discovery. Each of these methods involves the student experiencing mathematics for themselves and involves some form of experimentation and investigation. The directed discovery method contains a small element of discovery and requires very little initiative from the students. Dean [5] describes this as students being prodded along a pre - determined path. The guided discovery method begins with the teacher starting the lesson but then students having to use their own initiative in pursuing a mathematical investigation. 
This method brings more success to some students and less success to others, when compared with directed discovery [5]. Finally free discovery comes from the natural curiosity of the student [5]. Although it is not initiated by the teacher, he does have a part to play through providing encouragement and advice. Discovery methods of teaching serve the students better than the teacher simply writing questions and solutions on the board and the students rewriting them in their copies.

\subsection{Group Work}

Teachers providing opportunities for group work is one of the main ways in which knowledge can be constructed. Group work provides a social setting in which students can interact with each. Through such interactions, students can help each other, share ideas and conduct meaningful discussion. Such discussion is much more than a conversation. "It is purposeful talk on a mathematical subject, in which there are genuine student contributions and interactions" [2:132]. The primary role of the teacher is as facilitator and ensuring an even mix between the groups. For example it is often a good idea to merge students of different ability levels in each group in order to facilitate peer teaching and learning. Thus the main pedagogical principles which the authors consider important for the framework undoubtedly include practices such as problem solving, discovery methods and group work. These will be the main instructional practices on which the framework will be based. However, particular pedagogical principles which subscribe to the learning theories of behaviourism and social learning will also be evident in many if not all of the lessons. Transformational based activities of algebra are primarily rule and procedural based and are often taught best using behaviourist teaching strategies such as 'drill and practice' and whole class teaching. The framework will also include some instructional practices such as scaffolding as well as providing students with the opportunity to display traits of self-regulation and self-control.

\subsection{Integrating the Perspectives into one Framework}

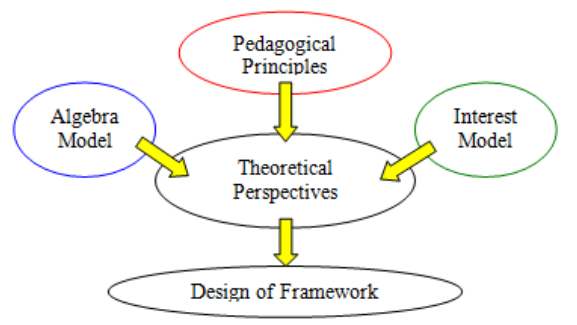

Figure 3. Integrating the Theoretical Perspectives into one Framework
The challenge for the authors was to combine the three theoretical perspectives, each of which has something special to offer into a viable integrated framework. Kieran's [10] model for conceptualising algebraic activity determines that there are three important components of school algebra namely generational activities, transformational rule-based activities and global/ meta-level activities. Each activity is important, thus the framework had to place equal emphasis on each particular type. Hidi and Renninger [9] propose a four stage model of interest development. The model identifies situational interest as providing a basis for an emerging individual interest. The pedagogical principles consider various theories of learning and select instructional practices which subscribe primarily to the constructivism learning theory. Thus the framework must place equal emphasis on each particular type of algebraic activity and must make use of a variety of teaching methods. However it also must have a structure whereby each student's interest in algebra can be developed and nurtured through the stages. Each domain will now be looked at individually.

\subsubsection{Effective Teaching}

The issues which contribute to effective mathematics teaching are recognized in the literature. Emenalo [7: 365] submitted a list of what in his opinion certified an effective teacher. In short the list is as follows; an effective teacher of mathematics is one who;

a) Prepares good and standard lesson notes based on approved schemes of work.

b) Selects an appropriate method of teaching for any given topic.

c) Uses appropriate and adequate teaching aids to illustrate his/her lessons.

d) Motivates and inspires students.

e) Teaches students not to hate or fear mathematics, but to love and cherish it.

f) Evaluates appropriately.

g) Succeeds in maximising output from a given input.

h) Based on outcome of the evaluation, successfully reassesses and reorganises his course outline and lesson notes in relation to the approved curriculum.

This list undoubtedly certifies an effective teacher and was used by the authors when selecting the pedagogical principles for the framework. The pedagogical principles selected for the framework ensure a variety of such teaching methods, primarily based on a constructivist approach can be used throughout each lesson, for example problem solving, group work, guided discovery. Such pedagogical principles also permit the use of 
appropriate and adequate teaching aids in each lesson. Furthermore they allow the teacher to make the content fun and interesting and where possible relate it to the lives of students. It is hoped that this will motivate and inspire students and lead them not to hate or fear the subject, but to enjoy and appreciate it.

\section{Student Interest}

The issues which contribute to effective mathematics teaching link directly to the issues which can stimulate and maintain student interest in the subject as the teacher again plays a major role here. Helping them to fulfill this role is an important part of this framework. There are many recommendations offered throughout the literature. Firstly, it is important that teachers engage students in the topic. This can be done using certain aspects of the learning environment, such as modification of teaching materials and strategies, and how tasks are presented [8]. For example, interest may be stimulated by presenting educational materials in more meaningful contexts that illustrate the value of learning and make it more personally relevant to the students. This can also be done through a variety of games, puzzles, and hands-on activities, pending the particular topic. The selected pedagogical principles ensure that such resources are a central aspect of the framework. However, while actions such as games, puzzles, hands-on activities and bright illustrated presentations definitely trigger student interest, many of them fail to maintain the student's interest over time [13]. Thus the issue aroused of how the framework can nurture, utilise and indeed maintain academically relevant interest over time.

A study carried out by Mitchell [13] in the US found that the two main factors in maintaining student interest over time were meaningfulness of task and student involvement. Meaningfulness refers to students' perception of topics in mathematics as meaningful to their own lives. For example, presenting mathematics in more relevant contexts illustrates the value of the subject and makes it more personally relevant for the student. Meaningfulness appeared effective because content that is perceived as being personally meaningful to students is a direct way to empower students and hold their interest [13]. Involvement refers to the degree to which students feel they are active participants in the learning process. In Mitchell's study, involvement also appeared effective because when the process of learning is experienced as absorbing, then that process is perceived as empowering to students and will therefore hold their attention [13]. Basically, students are more interested when they learn by doing, as opposed to sitting and listening. This is advocated through the pedagogical principles of constructivism.

Similar to empowering students through meaningfulness and involvement, affording students more choice, or promoting perceived autonomy can also promote individual interest [8]. This is incorporated into the framework through the influence of the social learning theory on the pedagogical principles. This theory encourages the students to become self-controlled and self-regulated learners. Del Favero et al. [6] also suggested that several forms of social interaction may also support the development of interest at various stages. This view was backed up by Hidi and Harackiewicz [8] who found that working in the presence of others resulted in increased interest for some individuals. Furthermore Del Favero et al. [6] determines that problem-solving often can maintain interest by making students aware of inadequacies or inconsistencies of their previous knowledge of a topic, thus encouraging further exploration of concepts and ideas. Thus both the work of Hidi and Harckiewicz [8] and Del Favero et al. [6] supports the case for the promotion of group work and discussion in lessons, which are again endorsed in the framework by the constructivist teaching approach.

\section{Algebra}

Perhaps the biggest issue which can contribute to effective mathematics teaching for interest in the topic of algebra is to provide understanding and purpose to the abstract theory. Despite the topic's obvious importance students are unable to see the everyday use of algebra in their own lives. They are unlikely to see their parents solving equations or rewriting expressions. In fact, they are unlikely to see anyone around them use such algebraic manipulations. Informing a 12 year old student that they will need algebra to get a job is unlikely to be a motive for learning. Thus, it is very difficult for students to take an interest in a topic in which they can see no immediate relevance. What students learn is a collection of rules to be memorised and tricks to be performed having no logical coherence, very little connection with previously learned arithmetic, and no applications in other school subjects or in the outside world [12]. The challenge for the framework is to find ways of teaching that create classroom environments which allow students to learn with understanding and generate a genuine interest in the topic. If students are to learn algebra, ways to reach those who are unmotivated or uncooperative must be found. The pedagogical principles and strategies for interest development discussed in the previous sections propose different methods aimed at making learning more meaningful and interesting. Such 
methods aim to provide a purpose and to bring a more concrete understanding of algebra to students. This need for a more concrete understanding is because the great majority of learners need visual materials to develop mathematical ideas [2]. Visual demonstrations can help some students who are unable to deal with such abstraction theoretically. Other methods proposed such as the use of quizzes and games can provide a purpose to the algebraic activity for the students and help relate the topic to their everyday lives, while not neglecting the rules and procedures.

\section{Integration}

It is clear there is an obvious overlap between effective teaching and student interest. Each theoretical perspective, although connected to different domains share many similar characteristics, and different aspects of each overlap and interlink with each other. This made it easier for the authors to integrate the perspectives into a viable framework to promote interest in algebra through effective teaching. For example Hidi and Renninger's [9] model suggest that situational interest in students is best stimulated and maintained through the meaningfulness of tasks and their personal involvement in hands on activities. Such strategies all coincide with a constructivist approach to teaching, incorporating problem solving, group work and discovery. These strategies also coincide with promoting understanding and providing purpose to the rule based activities of algebra which is the main focus of Kieran's [10] model for conceptualising algebraic activity. This is a general example to show how the three perspectives are combined into one framework. However considerable work has yet to be done reconciling and blending them to produce effective teaching materials.

\section{Future Work}

- Teaching materials based on the framework must be developed. These materials must place equal emphasis on each particular type of algebraic activity and must make use of a variety of teaching methods. However they must also have a structure whereby each student's interest in algebra can be developed and nurtured through the phases.

- Implementation:

Once the materials have been developed the authors plan to implement the intervention in a number of second level schools in Ireland. This will require the full co-operation of researcher, teacher and students. Randomly assigned control and experimental groups will be used in each school.
- Evaluation:

Pending successful implementation, the necessary evaluation will be carried out. There are four key parameters, outlined by Shapiro [18] by which intervention research can be evaluated, namely;

o Treatment effectiveness,

o Treatment integrity,

o Social validity,

o Treatment acceptability.

These measures will involve the collection of both qualitative and quantitative data.

- Provided the evaluation reaches a successful conclusion, an attempt will be made to model the intervention into an effective CPD program. Access to the intervention will be provided to more schools and teachers. Support networks for teachers using the intervention will also be put in place. In addition the framework will be used to design similar interventions to different topics in mathematics and indeed other subjects.

\section{Conclusion}

The issue of boosting numbers taking Higher Level for Junior and Senior Cycle mathematics is a serious issue within mathematics education in Ireland today. Through designing this framework for the development of a teaching intervention, it is anticipated that positive outcomes will be achieved. It is intended that a wide variety of teaching methodologies, materials and activities will be used throughout the intervention and a conscious effort will be made to relate the content to the everyday lives and interests of the students. Thus, by maintaining student interest through good teaching, more students will remain engaged and go on to complete Higher Level mathematics at second level.

\section{References}

[1] Artique, M. and Assude, T. (2000) 'Teaching and Learning Algebra: Approaching Complexity through Complimentary Perspectives' [online], available: http://pepite.univ-lemans.fr/English/4-txtBGMA_icm2001.pdf [accessed December 2008].

[2] Backhouse, J., Haggarty, L., Pirie, S. and Stratton, J. (1992) 'Improving the Learning of Mathematics', London: Cassell.

[3] Chief Examiners Report (1999; 2003; 2006) Junior Cert Examinations - Mathematics [online], available: http://www.examinations.ie/index.php?l=en\&mc=en\&sc =c r[accessed January 2010].

[4] Choike, J.R. (2000) 'Teaching Strategies for Algebra for All’, 93 (7), 556 - 560. 
[5] Dean, P.G. (1982) Teaching and learning mathematics, London: The Woburn Press.

[6] Del Favero, L., Boscolo, P., Vidotto, G. and Vicentini, M. (2007) 'Classroom discussion and individual problemsolving in the teaching of history: Do different instructional approaches affect interest in different ways?', Learning and Instruction, 17, 635 - 657.

[7] Emenalo, S.I., (1994) 'Evolving mathematics culture through effective teaching - the Nigerian experience', International Journal of Mathematics Education and Science Technology, 25 (3), 363 -366.

[8] Hidi, S and Harackiewicz, J.M. (2000) 'Motivating the Academically Unmotivated: A Critical Issue for the 21st Century' Review of Educational Research, 70 (2) 151-179.

[9] Hidi, S. and Renninger, A. (2006) 'The four-phase model of interest development' Educational Psychologist 41, 111-127.

[10] Kieran, C. (1996) 'The changing face of school Algebra' in 8th international congress on mathematical education selected lectures, 271 - 286. S.A.E.M. 'THALES'.

[11] Kieran, C. (2004) 'The Core of Algebra: Reflections on its Main Activities' in Stacey, K., Chick, H. and Kendal, M. (2004) The Future of the Teaching and Learning of Algebra - The $12^{\text {th }}$ ICMI Study, London: Kluwer Academic Publishers.

[12] MacGregor, M, (2004) Goals and content of an algebra curriculum for the compulsory years of schooling in K. Stacey., H. Chick, \& M. Kendal The Future of Teaching and Learning of Algebra. The $12^{\text {th }}$ ICMI Study. (pp. 313-328). London: Kluwer.

[13] Mitchell, M. (1993) 'Situational Interest: Its Multifaceted Structure in the Secondary School Mathematics Classroom', Journal of Educational Psychology, 85 (3), 424 - 436.

[14] Neyland, J. (1995) Mathematics Education - A Handbook for Teachers (Vol. 2), New Zealand: Wellington College of Education.

[15] Ormond, J.E. (1999) Human Learning (3 ${ }^{\text {rd }}$ Edition) [online], available: www.teachnet.edb.utexas.edu/ lynda_abbott/Social.html [accessed December 2007].

[16] Programme for International Student Assessment (PISA) (2003) Learning for Tomorrow's World- First Results from PISA 2003, OECD [online] available: http://www.pisa .oecd.org/document/55/0,3343,en_32252351_32236173_3 3917303_1_1_1_1,00.html [accessed March 2008].

[17] Sandoval, J. (1993) The history of interventions in school psychology [online] available: http://www.sciencedirect.com [accessed February, 2009].

[18] Shapiro, E.S. (1987) 'Intervention Research Methodology on School Psychology', School Psychology Review, 16 (3), 290 - 305.

[19] Snowman, J. and Biehler, R. (2006), Psychology Applied to Teaching (1 $1{ }^{\text {th }}$ Edition), Boston/ New York: Houghton Mifflin Company.

[20] State Examinations Commission (SEC) [online], available:

http://www.examinations.ie/index.php?l=en\&mc=st\&sc=r 10 [accessed September 2010]. 